\title{
British and American health care systems: a comparative economic perspective
}

\author{
MICHAEL W SPICER
}

\begin{abstract}
Despite its faults the British health system has traditionally been viewed by most Britons as relatively successful. Recently, however, there have been signs of stress. While the cost of the Health Service has grown from $£ 2000 \mathrm{~m}$ in 1970 to $£ 9400 \mathrm{~m}$ in 1979, hospital waiting lists have lengthened and staff morale, as shown by labour unrest, has deteriorated. Patrick Jenkin, Secretary of State for the Social Services, has warned that doctors, nurses, hospitals, and clinics must begin to be protected from the rising demand for health services and that the public must be educated to lower its expectations for health care. ${ }^{1}$ Concerned about the pressure of increasing health care costs on tax resources, the Government is investigating the possibility of increasing the part that health insurance plays in funding health services. Such a policy, if adopted, would mark a departure from the practice of financing health services almost entirely from tax revenues. But, as Cooper noted, it is important "not to swing from the finding that the NHS has been less than utopian to the advocacy of some other system which may prove to be a good deal worse in practice." 2
\end{abstract}

The British and American systems of health care represent quite different approaches to the financing and provision of health care. While private medicine is expanding in Britain, it still forms only a small part of medical care and the NHS is used by about $95 \%$ of the population. The British system is perhaps the closest in the non-communist world to a command economy in health care. The NHS has been termed the "only piece of pure socialism" of the postwar Labour government." Over $88 \%$ of NHS funds are drawn from general taxation, and services are provided to the public, usually free of charge, through a system of Government-owned hospitals and independent general practitioners under contract to the NHS. The American system is closer to a market economy in health care, with about $60 \%$ of health funds coming from private sources: consumers, private health insurance, industry, and philanthropic organisations. For the most part hospitals are owned by private non-profit institutions and most doctors are in private practice. Over $80 \%$ of the population carry some type of private health insurance and $70 \%$ of personal health care expenditure is paid by third-party payers: government, private insurance, and philanthropists.

From an economic perspective, each health care system needs to accomplish three important tasks. Firstly, a limit must be set on the resources devoted to health care; secondly, a means must be found to determine who will receive the health care; and, thirdly, incentives must be provided so that health care resources are used efficiently. I have attempted to analyse how the British and American systems accomplish these tasks, and to identify the implications for reform of the British system, including insurance financing.

\footnotetext{
Graduate School of Public Affairs, University of Colorado, Colorado Springs, Colorado 80907, USA

MICHAEL W SPICER, PHD, associate professor in public administration and economics
}

\section{Limiting the resources for health care}

The amount of resources used for health care needs to be limited or rationed because the demand for health care is potentially insatiable. While health planners may talk of health needs as something tangible and finite, modern health systems have shown themselves perfectly capable of absorbing all the resources that nations are willing to allocate to them. There is no clear limit to the extent of sickness in a society, and the willingness of doctors to identify and treat that sickness is limited only by resources and technology. Health or sickness is not always easy to determine; medicine is not an exact science and hence additional consultations, tests, drugs, treatments, and screening may easily be justified on medical grounds. The report of the Royal Commission on the National Health Service stated, "To believe that one can satisfy the demand for health care is illusory, and that is something that all of us, patients and providers alike, must accept." 4

In America resources are limited, at least in principle, by price. In Britain, where most health services are provided at a zero price, the budgetary process is, in principle, the basis for limiting expenditures on health care. The demands of the NHS are balanced against the demands of other Government services and general economic policy.

The British system may be more effective because the power of price to ration in the United States has been eroded by the growth of third-party payments for health care costs. Such payments reduce the cost of health care at the point of consumption and so reduce the incentive of patients and providers to economise on their use of health care services. Indeed, in the case of hospital care, where patients pay directly only $6 \%$ of costs, the incentive to economise seems almost entirely absent. It is true that the British system of zero prices also encourages higher demand for services, but the ability of the NHS to meet this demand is constrained by the budgetary process. This may partly explain the differences in the cost of the two systems. Health care expenditure in 1976 accounted for $5.8 \%$ of the gross national product (GNP) in Britain compared with $8.6 \%$ in the United States. Since 1950 NHS expenditure adjusted for the general rate of inflation has increased by $3.6 \%$ a year, while in the United States health care expenditure has risen by $6.5 \%$ a year. While many factors, including different income levels and tastes, may help to explain this differential growth rate, the different rationing mechanisms may well have influenced it.

The importance of setting budget limits to health care expenditure in the absence of effective price rationing is also suggested by Canada's experience with national health insurance, where the introduction of budgetary ceilings seems to have slowed the growth: from 1971 to 1976 the share of GNP spent on health care actually fell from $7 \cdot 4 \%$ to $7 \cdot 1 \%$. Further evidence is provided by the experience of prepaid health care plans or health maintenance organisations in the United States. Under such plans subscribers pay a fixed capitation fee in return for comprehensive health care services. The total amount of fees collected by the plan provides a limited pool of resources from which health services for subscribers are financed. This seems 
to result in lower hospital admission rates and lower total costs for subscribers.

The apparent effectiveness of the NHS in limiting costs is not regarded universally as a virtue. Indeed, there is a widespread perception, particularly in Britain, that the Service is underfinanced. In evidence to the Royal Commission on the National Health Service the British Medical Association, perhaps not surprisingly, said, "An insufficient share of national resources has hitherto been allocated to the Health Services," and, "For some years now the money allocated by the Government to the Health Service has been quite inadequate to meet the demands made upon it by the public." Similar sentiments were expressed in evidence given by the Labour Party and the Trades Union Congress.

The argument for increased funding for the NHS is, however, weakened by the absence among developed countries of any observable association between resources allocated to health care and the population's standard of health. For example, life expectancy and infant mortality are virtually identical in Britain and the United States. As Fuchs noted, "Variations in mortality across and within countries do not seem to be related to the availability of physicians or other medical care inputs." 5 Mortality data provide only a crude indication of health, but recent research suggests that variations in the amount of health care resources have little impact on more specific indicators of health such as the incidence of high blood pressure in the population. Apparently, in developed countries health is affected far more by lifestyle, education, genetics, and environment than by the amount of medical care available.

\section{Determining who will receive health care}

Determining who will receive health care is perhaps the most controversial function that health systems perform. In Britain equal access to the NHS without regard to ability to pay is a major objective. In principle, this is provided by zero prices and universal coverage. Equality of access has not been a manifest goal of the American system, and medical care has traditionally been provided on the basis of willingness to pay. While government financial help is provided for the elderly and poor, coverage is far from complete. An estimated one-third of poor people are not eligible for benefits and the elderly must still incur substantial out-of-pocket costs when they are ill.

This suggests that access to health care is more equal in the NHS than in the American system. But at least two qualifications should be made. Firstly, despite remaining barriers of price the use of medical care in the United States is now greatest among low-income groups. Secondly, there is evidence that utilisation of NHS services by lower socioeconomic groups is lower than their higher rates of morbidity seem to warrant. A recent study by Collins and Klein, however, casts doubt on this evidence and suggests no consistent bias against lower socioeconomic groups in terms of access to health care. ${ }^{5 a}$

The virtual absence of price barriers creates a problem of access. As James Buchanan argued, with zero prices people will demand as consumers more health care than they will willingly finance as taxpayers. ${ }^{6}$ Queuing is therefore a likely outcome, and indeed queuing, particularly for hospital care, is viewed by some as the major defect in the British system. Cotton Lindsay, in a report critical of the NHS, argues that, "Health care is rationed in the NHS on the basis of people's willingness to suffer delay in its delivery. Access to health care under the NHS no longer goes to those willing to pay the most for it. It goes to those willing to wait the longest to receive it."7 While queuing is an important and probably inevitable consequence of zero prices, this last argument is somewhat misleading as it conveys an image of widespread inconvenience and suffering. In a recent survey of NHS patients undertaken for the Royal Commission $80 \%$ of respondents said that they were not caused inconvenience or distress by waiting for admission. ${ }^{8}$

Many people think that the access and queuing problems of the NHS would disappear if only sufficient funds were forthcoming. But this is doubtful. According to Cooper, NHS doctors seem to assess medical need as a function of current levels of provision. This is lent support by Martin Feldstein's statistical analysis of NHS hospital admission rates. Admission rates were found to be a negative function of the size of hospital waiting lists. ${ }^{9}$ It also helps explain why, despite a substantial increase in the number of hospital cases treated since 1949, waiting lists have not shortened. Queuing seems to be an almost inevitable consequence of the way in which the British have chosen to finance and provide health care.

\section{Efficiency in the use of resources}

While there is reason to believe that budgetary control has been fairly effective in limiting overall NHS expenditure, there is little reason to believe that budgetary control promotes the use of resources in a cost-effective or efficient manner. As noted by the Royal Commission, any savings that budget holders in the NHS manage to achieve are likely to be transferred to cover expenditure elsewhere in the Service. This common budgeting practice penalises the efficient and rewards the inefficient. It is not surprising, therefore, that there is evidence of considerable waste in the NHS. Hospital stays vary considerably for the same medical condition. General practitioners differ widely in their referrals of patients to specialists and hospitals. Most of the medical procedures now in use have not been rigorously tested or their value proved. Furthermore, expensive medical equipment is often purchased without proper prior evaluation.

While in principle a far more cost-effective use of resources might be expected in a market system of health care, the presence of third-party payments again creates problems, particularly in hospital care. With almost complete hospital insurance coverage patients, guided by their doctors, have little incentive to shop around for low-cost hospital care. Also, hospitals are usually reimbursed retrospectively on a fee-for-service basis. As a result, there is little incentive for health care providers to seek either more cost-effective means of delivering hospital care or more cost-effective alternatives to admission to hospital. It is not difficult, therefore, to find in the American system instances of waste similar to those found in the NHS-for example, variations in hospital admission rates and hospital stays.

Lindsay argues that inefficiency may be greater in the NHS than in the American system. ${ }^{7}$ The basis for his argument is that durations of hospital stay for given medical diagnoses and procedures are longer in Britain than in the United States. Whether this particular indicator, however, is a representative measure of relative inefficiency is open to question. Feldstein's research shows that duration of stay increases with bed availability. ${ }^{9}$ Since the stock of hospital beds per caput is $24 \%$ higher in Britain than in the United States, longer durations of stay would therefore be expected. This is not to deny that the NHS may be inefficient in this respect but rather to point out that the NHS may score better on other performance indicators. For example, as Cooper noted, "Hospital surgeons in the USA manage to find twice as many patients in need of surgery as do their British counterparts,"2 a differential that may partly be due to the fact that in Britain patients are customarily referred for specialist advice by general practitioners, unlike in the United States, where patients can go direct to specialists. An examination of a broader range of performance indicators would, therefore, be necessary before firm conclusions could be drawn regarding relative inefficiency in the two systems.

\section{Summary and implications for reform}

A comparative analysis of the two systems indicates that the British system scores relatively well in terms of rationing the resources going to health care, despite zero prices, because of 
the limits set by the budgetary process. In terms of access zero prices and comprehensive coverage probably promote greater equality of access to health services in the British system but barriers remain and queuing is a problem. Finally, incentives for efficiency in the management of available health care resources are weak in both systems.

This analysis raises serious questions regarding the merits of moving towards a greater use of insurance in financing the NHS. There are, no doubt, those who would argue that it is dangerous to extrapolate from the American experience, given differences in the cultural, political, and social backgrounds of the two systems. But my comparative analysis suggests that the weaknesses of the American health care system are a logical consequence of the incentives provided by extensive third-party coverage. If Britain were to move in the direction of insurance financing, coverage would be even more complete than in the United States. Substantial insurance deductibles or coinsurance* rates, which might lessen the problems of insurance financing by making consumers more cost conscious, are not likely to be required, given the British commitment to equal access and over 30 years of free health care. Hence, the likely outcome of extensive insurance financing in Britain would be higher costs and no visible improvement in health levels. Costs, of course, might be contained by imposing limits on the total expenditure on health care, but if this were done it is difficult to see how an insurance-financed system would differ substantially from a tax-financed system.

This does not mean that improvement could not be made in the delivery of health care in Britain; in particular, improved efficiency is needed in the management of resources. This need is likely to grow in the future because of the rapid rate of technological innovation in medicine that promises an increasing array of sophisticated but expensive medical procedures, drugs, and equipment. Certainly, improved information and analysis are necessary, but even more fundamental is the need to change incentives in the British health care system so that such information and analysis is properly used.

William Niskanan suggested that efficiency in government bureaucracies may be improved by providing monetary rewards to bureaucrats. ${ }^{10}$ Such rewards, he argues, would induce bureaucrats to reduce costs below approved budget levels. These rewards might take the form of personal rewards or allowing bureaucrats to spend a proportion of savings they achieve on a restricted set of allowable activities. The Royal Commission, pursuing a similar line of argument, suggests that NHS budget holders should be permitted to spend budget savings as they think best and possibly be allowed to carry over a greater portion of savings to future budget periods. Inevitably, there is a risk

*A deductible is a flat sum of money for medical services which must be paid by patients before their insurance picks up all or a part of the remainder. Coinsurance refers to an arrangement whereby insurance pays only a certain fraction of medical costs incurred by a patient. that such incentives would encourage budget holders simply to cut back on service provision or quality. Therefore, measures of service output would need to be developed and monitored.

A more radical alternative would be to encourage the development of competing prepaid health plans such as exist in the United States. Consumers enrolled in such plans pay a fixed charge and in return receive comprehensive medical services, including hospital care. The Government could provide health vouchers to consumers, who could use them to enrol in the plan of their choice or to procure NHS services. All health care providers, private and public, would then be reimbursed by the Government on the basis of the number of vouchers received. This would in effect extend to the entire health care system the capitation mechanism already used to reimburse GPs. Health care providers would have an incentive to seek low-cost methods of providing care and, at the same time, competition would provide a check on the quantity and quality of services provided. Such a radical approach requires substantial study before being introduced. As Rudolf Klein noted, such an approach "makes optimistic assumptions about the information available to consumers and about the willingness of health care providers to engage in competition." 11 Nevertheless, the American experience with prepaid health care plans suggests that the approach is worth investigating.

The benefits from moving to greater insurance financing of health services are doubtful. Far more promising is an examination of alternative ways to promote incentives among health care providers to seek out more efficient ways of providing services. I believe that without such a change in incentives the NHS will face increasingly severe difficulties in continuing to provide quality health care at a relatively low cost.

\section{References}

1 Anonymous. The Times 1981 January $24: 6$.

2 Cooper MH. Rationing health care. New York: John Wiley and Sons, 1975.

3 Eckstein HH. The English health service. Oxford: Oxford University Press, 1959.

4 Royal Commission on the National Health Service. Report. Cmnd 7615. London: HMSO, 1979.

${ }^{5}$ Fuchs VR. Who shall live? New York: Basic Books, 1974.

5a Collins E, Klein R. Equity and the NHS: self-reported morbidity, access, and primary care. $\mathrm{Br} M e d \mathcal{F} 1980 ; 281: 1111-5$.

6 Buchanan JM. Inconsistencies in the National Health Service. Occasional paper No 7. London: Institute of Economic Affairs, 1966.

${ }^{7}$ Lindsay CM. National health issues: the British experience. Tunbridge Wells : Roche Laboratories, 1980.

${ }^{8}$ Gregory J. Patients' attitudes to the hospital service. Royal Commission on the National Health Service, research paper No 5. London: HMSO, 1978.

${ }^{9}$ Feldstein MS. Economic analysis for health service efficiency. Chicago: Markham, 1968.

10 Niskanen WA. Bureaucracy: servant or master? London: Institute of Economic Affairs, 1973.

${ }^{11}$ Klein R. Who decides? Patterns of authority. Br Med $\mathcal{f}$ 1978;ii:73-4.

(Accepted 9 February 1981) 